\title{
Characteristics and Adverse Events in Acute Coronary Syndrome Patients with a History of Peripheral Arterial Disease
}

\author{
Iran Castro $^{10}$ and Hugo Fontana Filho ${ }^{1}$ \\ Fundação Universitária de Cardiologia - Instituto de Cardiologia (ICFUC), ${ }^{1}$ Porto Alegre, RS - Brazil \\ Short Editorial related to the article: Clinical Characteristics and Adverse Events in Acute Coronary Syndrome Patients with a History of \\ Peripheral Arterial Disease
}

Cardiovascular diseases (CVD) are the leading cause of death in the world, ${ }^{1}$ with increasing numbers of cases in low and middle-income countries. In Brazil, it is estimated that 350,000 patients die each year due to CVD. ${ }^{2}$ The relationship between acute coronary syndrome (ACS) and peripheral atherosclerotic disease (PAD) is well established. ${ }^{3,4}$

Cross-sectional studies carried out in countries with genetic characteristics different from ours help us to evaluate the possible relationship between the characteristics of the patients evaluated and the increase in cardiovascular risk, and, despite their limitations, are good hypothesis generators.

The present study ${ }^{5}$ analyzed the characteristics of patients with ACS and PAD, showing that advanced age, diabetes,

\section{Keywords}

Cardiovascular Diseases; Acute Coronary Syndrome; Peripheral Arterial Disease/complications; Diabetes Mellitus; Myocardal Infarction; Risk Factors.

\author{
Mailing Address: Iran Castro • \\ Instituto de Cardiologia - Métodos Gráficos - Av. Princesa Isabel, 395 Santana. \\ Postal Code 90620-000, Porto Alegre, RS - Brazil \\ E-mail: icastro@cardiol.br
}

DOI: $10.5935 / a b c .20190177$ worse lipid profile and multiarterial disease were more prevalent in patients with ACS and PAD than in patients with ACS and without PAD. In addition, it suggested that patients with such an association have a worse prognosis.

Limitations of the present study were the facts of its retrospective analysis and the exclusion of patients at higher risk (prior acute myocardial infarction, acute myocardial infarction caused by thrombus detachment, intravascular surgery, patients with cardiogenic shock and post-cardiac arrest and gastrointestinal bleeding on admission), which could have shown an even higher risk in such patients, considering that generally patients with associated PAD have greater complications and worse prognosis. It is also worth noting that it was carried out in a single center.

However, the present study has great value for showing once again, as previous studies have demonstrated, ${ }^{6}$ the worsening of the prognosis of patients with ACS and PAD and which risk factors are most prevalent in this population, making possible the detection of subgroups of patients with ACS and PAD are more susceptible to a worse outcome and in this way emphasize their strict control. It is also necessary to offer the best treatment evidenced in the literature to such patients since real-life studies have shown that despite the higher risk of patients with ACS and PAD, they frequently receive less drugs with established benefit. $^{7}$

\section{References}

1. Organização Mundial da Saúde (OMS); Organização Pan-Americana da Saúde (OPAS) [Internet]. Doenças cardiovasculares. Internet. (Acesso em 2019 abr 23). Disponível em https://www.paho.org/bra/index.php?option=com_co ntent\&view $=$ article\&id = 5253: doenças-cardiovasculares\&ltemid $=109 \overline{6}$

2. Sociedade Brasileira de Cardiologia. [Internet]. Notícias. Cardiômetro da Sociedade Brasileira de Cardiologia já registra mais de 78 mil mortes por doenças cardíacas nos primeiros dias do ano. [Acesso em 2018 mar 24]. Disponível em: http://www.cardiometro.com.br

3. Taimur SD, Chowdhury MZ, Hakim E. Correlation between peripheral arterial disease and coronary artery disease in Bangladeshi population- a five years retrospective study. University Heart Journal. 2017;11(2):79-84.

4. Imori Y, Akasaka T, Ochiai T. Co-existence of carotid artery disease, renal artery stenosis, and lower extremity peripheral arterial disease in patients with coronary artery disease. Am J Cardiol .2014;113(1):30-5.

5. Yun-Peng K, Li-Ying C, Tie-Duo K, Wen-Xian L. Clinical characteristics and adverse events in acute coronary syndrome patients with a history of peripheral arterial disease. Arq Bras Cardiol. 2019; 113(3):367-372

6. Inohara T, Pieper K, Wojdyla DM, Patel MR, Jones WS, Tricoci P, et al. Incidence, timing, and type of first and recurrent ischemic events in patients with and without peripheral artery disease after an acute coronary syndrome. Am Heart J. 2018 March; 201:25-32.

7. Cordeiro F, Mateus PS, Ferreira A; Investigators of the Portuguese Registry of Acute Coronary Syndromes (ProACS)1. Short-term prognostic effect of prior cerebrovascular and peripheral artery disease in patients with acute coronary syndrome: Can we do better? Eur Heart J Acute Cardiovasc Care. 2018;7(7):652-60. 